\title{
Determinants of self rated health for Canadians with chronic disease and disability
}

\author{
Cheryl A Cott, Monique A M Gignac, Elizabeth M Badley
}

\begin{abstract}
Objective-To identify the factors associated with self rated health of people with and without chronic health conditions or long term disability.

Setting-Canadian household population. Design-Analysis of 1994/95 National Population Health Survey interview data with 13995 respondents aged 20 years and older. Determinants of poor and good compared with excellent health were examined using multivariate nominal logistic regression. Factors included in the analyses were illness related (chronic disease, long and short-term disability, and pain) demographic, lifestyle (smoking, physical activity, drinking), and social psychological resources (mastery, chronic stress, distress, self esteem, and social support).

Results-Illness related variables were associated with poor health, with smaller but significant contributions from demographic and lifestyle factors. Psychological resources, especially high mastery and self esteem, are associated with better health in those with chronic conditions or disability. Conclusion-The determinants of self rated health for people with chronic illness and disability make the greatest contribution to the findings for the overall population.

(F Epidemiol Community Health 1999;53:731-736)
\end{abstract}

Evaluation Unit, The

Arthritis and Immune

Disorders Research

Unit, The Toronto

Hospital

C A Cott

M A M Gignac

E M Badley

Department of Physical Therapy and Graduate Department of Rehabilitation Science, University of Toronto

C A Cott

E M Badley

Department of Public Health Sciences, University of Toronto M A M Gignac

E M Badley

Correspondence to: Dr C Cott, Department of Physical Therapy and Rehabilitation Science, University of Toronto, 256 McCaul Street, Toronto, Ontario, Canada, M5T 1W5

Accepted for publication 3 March 1999 Self rated health has been identified as an important indicator of the multi-dimensional construct, health. Self evaluations of health have been found to be related to a wide range of outcomes from well being to service use, and are a significant predictor of mortality ${ }^{1-6}$ and morbidity ${ }^{7-9}$ Although functional disability and the absence of chronic diseases are important to the formation of subjective health perceptions, people with chronic diseases can also report good health. Data from the 1990 Ontario Health Survey showed that $79 \%$ of those with chronic disorders reported that their health was good to excellent, as did over $50 \%$ of those with long term disability, including $40 \%$ of those with mobility disabilities. ${ }^{10}$ These data suggest that despite the presence of chronic illness and disability, most people perceive their health in favourable terms. This raises questions about the distinction between people's self rated perceptions of their health status and a diagnosed medical condition or disability. When asked to rate their overall health, people may use additional information that goes beyond a simple summing of their medical conditions or the level of disability that those conditions engender.

Very little work has been directed to the predictors of self rated health in the presence of chronic disorders. Given the literature on the positive health outcomes associated with self rated good health, the promotion of "good" health and the prevention of illness in people with chronic disease and disability would seem to be a priority. A better understanding of the link between self reported health and chronic and disabling conditions will have implications for the development of strategies to improve the health of the population and may reduce the need for formal health care. The primary objective of this research is to identify the determinants of self rated health in the overall Canadian population and in people with and without disability and chronic illness.

The high prevalence of chronic conditions and disability in Canada make understanding the predictors of self rated health in this group an important issue. In the 1991 General Social Survey (GSS), almost two thirds of Canadians reported at least one chronic health problem, of which skin and other allergies, arthritis and rheumatism and hypertension were the most common. ${ }^{11}$ Long term disability is reported by $10-15 \%$ of the Canadian adult population ${ }^{12} 13$ with the major reported causes of long term disability including arthritis and rheumatism, back disorders, heart disease and respiratory disorders. ${ }^{10}$

Perceptions of good health among Canadi- 
Table 1 Dichotomised predictive variables by block

\begin{tabular}{|c|c|c|}
\hline \multicolumn{2}{|l|}{ Block 1: Illness related factors } & \multirow{2}{*}{$\begin{array}{l}\text { (Comparison group) } \\
\text { no chronic health problem or disability }\end{array}$} \\
\hline Chronic condition or disability & $\begin{array}{l}\text { any chronic health problems and/or long term } \\
\text { disability that restricted activity lasting or expected to } \\
\text { last } 6 \text { months or more }\end{array}$ & \\
\hline Pain severity & moderate or severe & mild or none \\
\hline Two week disability & presence of any disability in last 14 days & no disability in last 14 days \\
\hline \multicolumn{3}{|l|}{ Block 2: Individual demographic variables } \\
\hline Age & 55 years old and over & less than 55 years old \\
\hline Marital status & married (married/common law/partner) & $\begin{array}{l}\text { not married (single, widowed, divorced, } \\
\text { separated) }\end{array}$ \\
\hline Gender & female & male \\
\hline Education & less than post-secondary education & any post-secondary education \\
\hline Employment status & not currently employed & currently employed \\
\hline Income & low, lower-middle or middle & upper-middle or upper \\
\hline \multicolumn{3}{|l|}{ Block 3: Personal health practices } \\
\hline Physical activity & active (active or moderate) & inactive \\
\hline Type of smoker & ever smoked & never smoked \\
\hline Type of drinker & regular drinker & not a regular drinker \\
\hline \multicolumn{3}{|l|}{ Block 4: Social psychological resources } \\
\hline $\begin{array}{l}\text { Perceived social support ( } 4 \text { questions re: presence of } \\
\text { social support) }\end{array}$ & low (1, 2 or 3 yes responses) & high ( 4 yes responses) \\
\hline Mastery (Pearlin and Schooler's Mastery Scale ${ }^{25}$ ) & low to moderate (score of $2-20$ ) & high (score of 21-28) \\
\hline Self esteem (Rosenberg Self esteem Scale ${ }^{26}$ ) & low to moderate (score of $1-20$ ) & high (score of $21-24$ ) \\
\hline Chronic stressors & 2 or more & 0 or 1 \\
\hline Distress (Kessler and Mroczek's index of distress ${ }^{27}$ ) & intermediate or high (score of 4 or more) & no or low (score of 1 to 3 ) \\
\hline
\end{tabular}

include: (1) illness related factors including any reported chronic health condition or long term disability, severity of pain and short-term disability; (2) individual demographic factors including age, marital status, gender, education, employment status and income; (3) personal health practices including level of physical activity, smoking and alcohol use; and, (4) social psychological resources such as perceived social support, mastery, self esteem, chronic stress and distress. Furthermore, we hypothesise that factors associated with self rated health will differ for those with and without chronic illness and disability.

\section{Method}

This project used data from the Health File of the 1994 National Population Health Survey (NPHS). The sample design of this survey has been described elsewhere. ${ }^{24}$ The target population included all household residents in each of the Canadian provinces, excluding populations on Indian reserves, Canadian Forces Bases, and some remote areas of Quebec and Ontario. The survey used a stratified two stage design for data collection. At the first stage, information about all household members was obtained from one knowledgeable household member in all dwellings. In the second stage, a person, 12 years of age or over, was selected randomly from each household for a more in depth interview including additional components on self rated health, health status, health behaviours and risk factors, life events, stress, and psychological variables $(n=17626)$.

We restricted our analyses to respondents from the second stage who were 20 years of age or older ( $n=15779$ ), as questions relating to the psychological variables were not asked of the younger respondents. As we were also interested in conducting each step of the multivariate analysis on the same group of respondents, respondents who had a missing value for any of the variables being examined were excluded from the analysis $(n=1784)$. These exclusion criteria resulted in a sample size of 13995.
STATISTICAL ANALYSIS

In determining the predictors of self rated health, three multivariate analyses were performed for: (1) the overall sample; (2) those with reported chronic conditions or long term disability; and, (3) those with no reported chronic conditions or long term disability. The protocol for this analysis was approved by the Research Institute Ethics Committee. All analyses were conducted using SAS (Statistical Analysis Systems) package.

A polytomous model (for a multi-level categorical outcome variable) was used to determine the predictors of poor health compared with good or excellent health. We categorised the outcome variable, self rated health, into three groups: "excellent", which included ratings of excellent or very good self reported health (baseline), "good", and "poor", which included fair or poor self reported health. Thus, the likelihood of reporting good or poor health was predicted as compared with reporting excellent health. To facilitate the interpretation of the results and the modelling technique, all of the explanatory variables were dichotomised based on extensive preliminary analyses (see table 1). The chronic illness and disability variable was used as an explanatory variable only in the overall model and was used to stratify respondents in the other two models.

Using a nominal logistic regression technique, the likelihood of membership in one category of self reported health versus another category was predicted by a series of variables classified into the following conceptual blocks: (1) illness related factors; (2) individual demographic factors; (3) personal health practices; and, (4) social/psychological resources. All statistical tests were two tailed. Ninety five per cent confidence intervals were calculated for all odds ratios.

\section{WEIGHTING}

All data were weighted to be representative at the national level. For statistical testing, weights were rescaled so that the average weight equals one and further adjusted by the design effect 
Table 2 Bivariate relations between potential predictive variables and three levels of self reported health

\begin{tabular}{|c|c|c|c|c|c|c|}
\hline & \multicolumn{2}{|c|}{ Excellent/very good } & \multicolumn{2}{|l|}{ Good } & \multicolumn{2}{|l|}{ Fair/poor } \\
\hline & $\begin{array}{l}\text { number } \\
\text { (thousands) }\end{array}$ & $\%$ & $\begin{array}{l}\text { number } \\
\text { (thousands) }\end{array}$ & $\%$ & $\begin{array}{l}\text { number } \\
\text { (thousands) }\end{array}$ & $\%$ \\
\hline \multicolumn{7}{|l|}{1 Illness related factors } \\
\hline \multicolumn{7}{|l|}{ Chronic condition: } \\
\hline yes & 4989 & 49.9 & 3257 & 32.6 & 1756 & 17.6 \\
\hline no & 6025 & 77.1 & 1586 & 20.3 & 200 & 2.6 \\
\hline \multicolumn{7}{|l|}{ Pain: } \\
\hline moderate to severe & 965 & 29.9 & 1096 & 33.9 & 1170 & 36.2 \\
\hline none & 10050 & 68.9 & 3747 & 25.7 & 787 & 5.4 \\
\hline \multicolumn{7}{|l|}{ Two week disability: } \\
\hline yes & 869 & 40.6 & 597 & 27.9 & 675 & 31.6 \\
\hline no & 10150 & 64.7 & 4246 & 27.1 & 1281 & 8.2 \\
\hline \multicolumn{7}{|c|}{2 Individual demographic variables } \\
\hline \multicolumn{7}{|c|}{ Age groups: } \\
\hline $55+$ & 2161 & 44.4 & 1652 & 33.9 & 1057 & 21.7 \\
\hline$<55$ & 8853 & 68.4 & 3191 & 24.7 & 900 & 7.0 \\
\hline \multicolumn{7}{|l|}{ Marital status: } \\
\hline married & 7559 & 62.6 & 3343 & 27.7 & 1184 & 9.8 \\
\hline not married & 3455 & 60.3 & 1500 & 26.2 & 773 & 13.5 \\
\hline \multicolumn{7}{|l|}{ Gender: } \\
\hline female & 5668 & 60.2 & 2605 & 27.7 & 1135 & 12.1 \\
\hline male & 5347 & 63.6 & 2238 & 26.6 & 822 & 9.8 \\
\hline \multicolumn{7}{|l|}{ Education: } \\
\hline secondary or less & 3794 & 51.3 & 2365 & 32.0 & 1232 & 16.7 \\
\hline post-secondary & 7220 & 69.3 & 2478 & 23.8 & 725 & 7.0 \\
\hline \multicolumn{7}{|l|}{ Employment: } \\
\hline unemployed & 3288 & 47.7 & 2198 & 31.9 & 1409 & 20.4 \\
\hline employed & 7726 & 70.8 & 2645 & 24.2 & 548 & 5.0 \\
\hline \multicolumn{7}{|l|}{ Income: } \\
\hline low-middle & 4475 & 53.0 & 2613 & 30.9 & 1362 & 16.1 \\
\hline upper & 6539 & 69.8 & 2230 & 23.8 & 595 & 6.4 \\
\hline \multicolumn{7}{|l|}{3 Personal health practices } \\
\hline \multicolumn{7}{|l|}{ Physical activity: } \\
\hline inactive & 6238 & 57.0 & 3278 & 29.9 & 1438 & 13.1 \\
\hline \multicolumn{7}{|l|}{ Type of smoker: } \\
\hline ever & 6595 & 58.6 & 3235 & 28.7 & 1424 & 12.7 \\
\hline never & 4419 & 67.4 & 1608 & 24.5 & 533 & 8.1 \\
\hline \multicolumn{7}{|l|}{ Type of drinker: } \\
\hline regular & 7060 & 66.5 & 2766 & 26.1 & 785 & 7.4 \\
\hline not regular & 3954 & 54.9 & 2077 & 28.8 & 1172 & 16.3 \\
\hline 4 Social/psychological res & & & & & & \\
\hline Perceived social supp & & & & & & \\
\hline high & 10159 & 63.6 & 4233 & 26.5 & 1578 & 9.9 \\
\hline low & 1697 & 52.6 & 1010 & 31.3 & 520 & 16.1 \\
\hline Mastery: & & & & & & \\
\hline low & 5057 & 52.8 & 3018 & 31.5 & 1511 & 15.8 \\
\hline high & 5957 & 72.4 & 1826 & 22.2 & 446 & 5.4 \\
\hline Self esteem: & & & & & & \\
\hline low & 5207 & 55.1 & 2889 & 30.6 & 1361 & 14.4 \\
\hline high & 5807 & 69.5 & 1954 & 23.4 & 596 & 7.1 \\
\hline Chronic stressors: & & & & & & \\
\hline 1 or less & 5305 & 66.9 & 1900 & 23.9 & 731 & 9.2 \\
\hline 2 or more & 5709 & 57.8 & 2943 & 29.8 & 1226 & 12.4 \\
\hline Distress: & & & & & & \\
\hline no or low & 7720 & 69.0 & 2731 & 24.4 & 746 & 6.7 \\
\hline intermediate or high & 3294 & 49.8 & 2112 & 31.9 & 1211 & 18.3 \\
\hline
\end{tabular}

correction factors provided in the NPHS Public Use Microdata documentation. ${ }^{27}$ These adjustments do not affect parameter estimates such as means and odds ratios but allow for variance estimates to be more conservative while retaining the unequal probability of case selection.

\section{Results}

BIVARIATE ANALYSIS

Table 2 contains the bivariate relations between the independent variables and the three levels of health for the total population. As might be expected, excellent or very good health were reported by a higher proportion of those without chronic conditions or disability, whereas fair or poor health were reported more frequently by those with chronic conditions or disability. However, almost $50 \%$ of those reporting a chronic illness or long term disability did rate their health as excellent or very good. A similar pattern was found in relation to two week disability, where a higher proportion of those with no short-term disability reported excellent or very good health. More striking were the differences in severity of pain, with almost $70 \%$ of those with no pain reporting excellent or very good health as compared with only $30 \%$ of those with pain.

Almost $70 \%$ of those under age 55 reported excellent or very good health as compared with less than $41 \%$ of those over age 55 . A slightly higher proportion of men than women reported excellent or very good health and even less difference in levels of health were reported by those who were married (or common law) compared with those who were not.

Self rated level of health varied by education and income, with those with lower education or income being less likely to report excellent or very good health. Overall, over $70 \%$ of those who were employed reported excellent or very good health compared with less than half of those who were not employed.

A healthy lifestyle was also related to the reporting of excellent health, with lower proportions of those who were inactive or who were ever smokers reporting excellent or very good health. In contrast, regular drinkers were more likely to report excellent or very good health than non-regular drinkers.

Social psychological resources were also related to good health. Those with two or more chronic stressors or high levels of distress were less likely to report excellent or very good health. In contrast, those with higher levels of mastery and self esteem were more likely to report excellent or very good health. There was little difference in self reported health for those with high or low social support.

MULTIVARIATE ANALYSES

Tables 3-5 contain the results of the multivariate analyses. As hypothesised, all of the independent variables were significantly related to self rated health in at least one of the models, except for social support. Social support is therefore not included in these results.

\section{Total population}

Table 3 gives the results of the logistic regression model for the total population. Respondents with a chronic condition or long term disability were more likely to report good as compared with excellent health (OR 2.33) and much more likely to report poor as compared with excellent health (OR 4.73). A similar pattern was found for pain severity and two week disability although the odds ratios were somewhat lower for the latter.

Being over 55 years of age, female, less highly educated, and unemployed were all associated with poor health as compared with excellent, and of good health as compared with excellent health. Lower income was associated with poor health as compared with excellent health, but not of good health as compared with excellent health. Being married decreased the odds slightly of reporting good as compared with excellent health.

Being active decreased the odds of reporting of poor versus excellent health, and good 
Table 3 Predictors of self reported health in the total population, nominal logistic regression model: odds ratio with $95 \%$ confidence intervals for levels of health, using excellent and good self reported health as baseline

\begin{tabular}{|c|c|c|}
\hline & $\begin{array}{l}\text { Good compared with } \\
\text { excellent OR }(95 \% \text { CI) }\end{array}$ & $\begin{array}{l}\text { Poor compared with } \\
\text { excellent OR }(95 \% \mathrm{CI})\end{array}$ \\
\hline \multicolumn{3}{|l|}{1 Illness related factors } \\
\hline Any chronic condition or disability & $2.33(1.82,3.00)$ & $4.73(3.70,6.05)$ \\
\hline Pain severity (moderate/severe) & $3.22(2.69,3.86)$ & $6.84(5.64,8.29)$ \\
\hline Any two week disability & $2.59(2.10,3.18)$ & $3.27(2.63,4.08)$ \\
\hline \multicolumn{3}{|l|}{2 Individual demographic variables } \\
\hline Age 55 years or older & $1.48(1.19,1.82)$ & $2.53(2.03,3.14)$ \\
\hline Married & $0.79(0.66,0.96)$ & $0.89(0.74,1.07)$ \\
\hline Female & $0.72(0.60,0.87)$ & $0.63(0.52,0.76)$ \\
\hline Less than post-secondary education & $1.38(1.15,1.66)$ & $1.96(1.63,2.36)$ \\
\hline Not in the labour force & $1.68(1.35,2.09)$ & $2.17(1.74,2.70)$ \\
\hline Low income & $1.18(0.97,1.44)$ & $1.53(1.25,1.87)$ \\
\hline \multicolumn{3}{|l|}{3 Personal health practices } \\
\hline Physically active & $0.82(0.68,0.99)$ & $0.52(0.43,0.63)$ \\
\hline Ever smoked & $1.41(1.15,1.71)$ & $1.76(1.44,2.14)$ \\
\hline Regular drinker & $0.64(0.53,0.77)$ & $0.59(0.49,0.71)$ \\
\hline \multicolumn{3}{|l|}{4 Social/psychological resources } \\
\hline Mastery (low) & $1.19(0.97,1.47)$ & $1.52(1.23,1.86)$ \\
\hline Self esteem (low) & $1.32(1.10,1.60)$ & $1.92(1.59,2.32)$ \\
\hline Chronic stressors ( 2 or more) & $1.07(0.87,1.30)$ & $1.52(1.24,1.86)$ \\
\hline Distress (high) & $1.63(1.35,1.97)$ & $2.47(2.03,2.99)$ \\
\hline
\end{tabular}

Table 4 Predictors of self reported health in those with chronic illness and disability, nominal logistic regression model: odds ratio with 95\% confidence intervals for levels of health, using excellent and good self reported health as baseline

\begin{tabular}{lll}
\hline & $\begin{array}{l}\text { Good compared with } \\
\text { excellent OR }(95 \% \text { CI })\end{array}$ & $\begin{array}{l}\text { Poor compared with } \\
\text { excellent OR }(95 \% \text { CI })\end{array}$ \\
\hline $\begin{array}{l}\text { 1 Illness related factors } \\
\text { Pain severity (moderate/severe) }\end{array}$ & $3.10(2.55,3.76)$ & $7.15(5.78,8.85)$ \\
Any two week disability & $2.66(2.13,3.32)$ & $3.46(2.72,4.40)$ \\
2 Individual demographic variables & & \\
Age 55 years or older & $1.46(1.16,1.83)$ & $2.46(1.93,3.13)$ \\
Married & $0.78(0.63,0.95)$ & $0.89(0.72,1.10)$ \\
Female & $0.70(0.57,0.86)$ & $0.60(0.48,0.74)$ \\
Less than post-secondary education & $1.49(1.22,1.83)$ & $2.00(1.62,2.47)$ \\
Not in labour force & $1.77(1.39,2.26)$ & $2.46(1.91,3.15)$ \\
Low income & $1.23(0.99,1.53)$ & $1.62(1.30,2.03)$ \\
3 Personal health practices & & \\
Physically active & $0.71(0.57,0.87)$ & $0.48(0.39,0.60)$ \\
Ever smoked & $1.40(1.13,1.74)$ & $1.59(1.28,1.99)$ \\
Regular drinker & $0.64(0.52,0.78)$ & $0.63(0.51,0.77)$ \\
4 Social/psychological resources & & \\
Mastery (low) & $1.26(1.00,1.59)$ & $1.68(1.33,2.12)$ \\
Self esteem (low) & $1.34(1.09,1.64)$ & $1.81(1.46,2.23)$ \\
Chronic stressors (2 or more) & $1.06(0.85,1.32)$ & $1.38(1.10,1.73)$ \\
Distress (high) & $1.63(1.33,2.01)$ & $2.22(1.79,2.76)$ \\
\hline
\end{tabular}

Table 5 Predictors of self reported health in those without chronic illness and disability, nominal logistic regression model: odds ratio with $95 \%$ confidence intervals for levels of health, using excellent and good self reported health as baseline

\begin{tabular}{lll}
\hline & $\begin{array}{l}\text { Good compared with } \\
\text { excellent OR }(95 \% \text { CI) }\end{array}$ & $\begin{array}{l}\text { Poor compared with } \\
\text { excellent OR }(95 \% \text { CI })\end{array}$ \\
\hline $\begin{array}{lll}\text { 1 Illness related factors } \\
\text { Pain severity (moderate/severe) }\end{array}$ & $3.80(2.27,6.36)$ & $6.33(3.84,10.43)$ \\
Any two week disability & $2.16(1.11,4.20)$ & $2.63(1.39,4.99)$ \\
2 Individual demographic variables & $1.44(0.78,2.64)$ & $2.38(1.31,4.32)$ \\
Age 55 years or older & $0.93(0.57,1.51)$ & $1.00(0.63,1.61)$ \\
Married & $0.90(0.56,1.42)$ & $0.78(0.50,1.23)$ \\
Female & $0.92(0.58,1.47)$ & $1.44(0.91,2.27)$ \\
Less than post-secondary education & $1.22(0.73,2.06)$ & $1.41(0.85,2.34)$ \\
Not in labour force & $0.88(0.54,1.43)$ & $1.14(0.71,1.84)$ \\
Low income & $1.72(1.08,2.73)$ & $0.95(0.60,1.48)$ \\
Physically active & $1.77(1.03,3.02)$ & $2.52(1.49,4.27)$ \\
Ever smoked & $0.63(0.39,1.01)$ & $0.53(0.33,0.83)$ \\
Regular drinker & & \\
4 Social/psychological resources & $0.89(0.55,1.47)$ & $1.06(0.65,1.70)$ \\
Mastery (low) & $1.44(0.87,2.38)$ & $2.33(1.43,3.81)$ \\
Self esteem (low) & $1.30(0.76,2.23)$ & $2.12(1.25,3.58)$ \\
Chronic stressors (2 or more) & $1.83(1.10,3.02)$ & $3.20(1.96,5.23)$ \\
Distress (high) &
\end{tabular}

health versus excellent health. Being a regular drinker was associated with reporting better health, while being a regular smoker increased the odds of reporting poor health.

Having low self esteem or high levels of distress increased the odds of reporting poor versus excellent health and good versus excellent health. Having low mastery and more than one chronic stressor increased the likelihood of reporting poor health but not good health.

\section{With chronic illness and disability}

The model for persons with chronic illness and disability was very similar to that of the total population (table 4). As in the total population, pain severity and two week disability were associated with poor and good health as compared with excellent health, as were being older, female, less highly educated, and unemployed. Lower income was associated with poor health, whereas being married was associated with better health. The relations between physical activity, smoking and drinking were very similar to the total population. Finally, in terms of social psychological variables, low self esteem or high levels of distress were associated with poor versus excellent health and good versus excellent health. Having low mastery and more than one chronic stressor increased the odds of reporting poor, but not good, health.

\section{Without chronic illness and disability}

In terms of illness related factors (table 5), respondents with pain were more likely to report good health and much more likely to report poor health. However, two week disability was only predictive of poor versus excellent health. With respect to demographic factors, only age was associated with self reported health with those over 55 years of age being more likely to report poor health. Marital status, gender, education, income and employment status were not associated with self reported health for respondents without chronic illness or disability.

Being a smoker increased the odds of reporting poor versus excellent health, and good as compared with excellent health. The odds ratio is much higher (OR 2.52) for reporting poor versus excellent health for persons without chronic illness or disability who smoked as compared with the total population (OR 1.76) or persons with chronic illness and disability (OR 1.59).

Mastery was not a factor in self rated health for persons without chronic illness and disability. Respondents with higher levels of distress were more likely to report good as compared with excellent health and much more likely to report poor health. Having low self esteem and more chronic stressors were only associated with poor versus excellent health, but not good versus excellent health.

\section{Discussion}

Overall, our findings confirm the findings of other studies with respect to the predictors of self rated health. Most of these studies have considered the population as a whole, while we have considered self rated health in those with and without chronic illness and disability. Our findings suggest that the determinants of self rated health for persons with chronic illness and disability make the most important contribution to the findings for the overall population. That is, a major contribution to poor health in the population is the presence of 
chronic disorders, long term disability and pain. It is the determinants of self rated health for those who do not have chronic illness and disability that remain less clear.

Illness related variables such as pain and current health impact, as indicated by two week disability, made a major contribution to self ratings of health. This was the case for the total population and for those with chronic illness or disability. Individual demographic factors made a contribution to reported poor health in the population, as a whole, as well as both for those with or without chronic illness and disability. These findings concur with other studies. Higher levels of income and education were consistently associated with a greater probability of maintaining good self rated health in the Ontario Longitudinal Survey of Aging ${ }^{6}$ and, in the 1978-79 Canada Health Survey, unemployed Canadians reported significant differences in their self reported health in terms of greater global unhappiness, psychological distress, anxiety/depressive symptoms, short and long term disability and a number of health problems. ${ }^{14}$ Similarly, in other studies, increasing age has been associated with a tendency to report one's health as poor, as is gender. ${ }^{10}$

The contribution of personal health practices was relatively modest for the total population and persons with chronic illness and disability. Although personal health practices have been associated with health, their relation to self reported health is not clear. Perceived health is an important predictor of physical activity and exercise levels with persons with poor self perceived health less likely to engage in physical activity or exercise programmes. ${ }^{15}$ The negative consequences for smoking and alcohol misuse are generally well known in the population. However, the relation between these personal health practices, disability and self perceived health is not well understood. ${ }^{7}$ Other studies of alcohol use and self reported health have suggested a J shaped relation with moderate drinkers more likely to report better health than lifelong abstainers and heavy drinkers, who were more likely to report poor or average health. ${ }^{16}$ While we did not find a J shaped relation, our findings do support that regular drinkers report better health than those who do not report regular consumption of alcohol. There may be an association between alcohol intake, smoking and self rated health, although, in general, smoking was usually associated with poorer self rated health. ${ }^{16}$ Interestingly, our results indicate that personal health practices, particularly smoking, are important predictors of self rated health for persons without chronic illness and disability.

One of our most striking findings is the role of psychological factors in predicting self rated health. Previous population research on self reported health with persons with chronic conditions and disability has not included psychological factors. Instead, the focus has been largely limited to illness related and sociodemographic information. However, a variety of psychological factors have been associated with other health outcomes in other research. For example, high self esteem or self worth, as well as
KEY POINTS

- The determinants of self rated health for persons with chronic illness and disability make the most important contribution to the findings for the overall population.

- Pain and current health impact make a major contribution to self reported health.

- Low self esteem, chronic stress and high distress contribute significantly to poor self reported health.

- Low mastery is an important predictor of poor health only for persons with chronic illness and disability.

a sense of mastery or control over life experiences have been associated with a variety of behavioural outcomes, as well as psychological measures of well being. ${ }^{20}$ However, theories of how these variables promote health are not well developed. Zautra and $\mathrm{Hempel}^{28}$ propose that positive psychological states may provide people with a breather from stress, restore their depleted energy, and help them sustain their coping efforts. Similarly, Antonovsky ${ }^{29}$ proposes that psychological variables can help people avoid threat or danger and can help encourage people to engage in activities that are health promoting. (Antonovsky's sense of coherence scale $^{29}$ was included in preliminary analyses but was not included here as it contributed minimally to the models). High self esteem or self worth, as well as a sense of mastery or control over life experiences are hypothesised to protect people against environmental stressors and social strains. ${ }^{2025}$ Our results, for both persons with and without chronic illness and disability, suggest that the presence of low self esteem, chronic stress and high distress are significantly related to poor self rated health.

A particularly important finding in this study is that low mastery was an important predictor of poor health only for persons with chronic illness and disability. One possible explanation for this finding is that mastery acts as a kind of coping resource that protects people in times of stress. This explanation is similar to the stress buffering effect that some researchers hypothesise of social support. ${ }^{30}$ As such, mastery would have less impact on self reported health at times when there is little health related stress, as in the case where there is an absence of chronic illness and disability. Our findings are consistent with studies that have demonstrated a buffering effect for perceived control and functional impairment in older adults ${ }^{31}{ }^{32}$ and perceived control and adjustment to chronic illness. ${ }^{33}$

Social support has been linked to a variety of health related measures in previous research. A lack of social support and social integration has been found to relate to physiological strain, and can be a good indicator of health problems, including mortality risk, among the elderly. ${ }^{17-19}$ The lack of predictive value of social support in this study is probably attributable to measurement problems in the variable of interest, and represents a limitation of this study. There was little variability in the range of scores for this 
variable, thereby limiting its explanatory value. Another limitation is the cross sectional nature of the data, which along with other considerations, can limit the ability to explore causal relations.

The results of this study suggest a number of directions for future research. Firstly, it is important that future studies on self reported health distinguish between people with and without chronic conditions and disability and include information on psychological resources. Longitudinal research is also needed to further clarify the relative contribution of illness related variables and psychological resources and how they relate to health care utilisation. The NPHS is a longitudinal survey, but unfortunately the psychological variables were only included in the first wave (1994) and were not repeated in the 1996 wave. The processes by which these factors influence health warrant further investigation. As well, the way that social support is measured needs to be reconsidered in order to sufficiently identify variations within the population. Longitudinal research would also allow for investigation of the stability of psychological resources and their ability to predict the onset and course of chronic conditions and disability associated health care utilisation.

The finding of non-overlapping confidence intervals for chronic illness, pain, age, physical activity and distress suggests that any decrement in self rated health is important for these key variables. Moreover, given the large numbers of people who rated their health as good to excellent in this study, differences in good versus excellent health may be important to differentiate in future research by using three levels of self rated health.

These findings also have implications for practice and policy. The contribution of individual factors is relatively greater for those with chronic illness and disability as compared with those without, suggesting the importance of resources such as income and employment in this population. Although the contribution of lifestyle factors is relatively small, it points to the potential role of improving health behaviours in the population by increased physical activity and smoking cessation. The importance of psychological resources has implications for health promotion and health education fields in that current efforts to increase people's mastery and control may ultimately be associated with improvements in self rated health. Furthermore, as poor self rated health has been associated with increased health care utilisation, ${ }^{34}$ these efforts to improve people's self rated health could result in decreased health care utilisation.

The authors would like to thank Joanne Daciuk, Margie Parthimos and Peter Wang for their assistance with the data analyses and Christine Dixon for her assistance with the typing of the tables.

Funding: this study was supported by the Ontario Ministry of Health, Health System-Linked grant to the Arthritis Community Research and Evaluation Unit (ACREU) and by Health Canada and Statistics Canada, funded by the National Health Research and Development Program (NHRDP)

Conflicts of interest: none.
1 Mossey JM, Shapiro E. Self-rated health: A predictor of mortality among the elderly. Am 7 Public Health $1982 ; 72: 800-8$

2 Kaplan GA, Salonene JT, Cohen RD, et al. Social connections and mortality from all causes and from cardiovascular disease: Prospective evidence from Eastern Finland. Am f Epidemiol 1988;128:370-80.

3 Sorenson KH. State of health and its association with death among old people at three-years follow-up. Dan Med Bull 1988;35:597-600

4 Wannamethee G, Shaper AG. Self-assessment of health status and mortality in middle-aged British men. Int $\mathcal{F}$ Epidemiol 1991;20:239-45.

5 Idler EL, Kasl SV, Lemke JH. Self-evaluated health and mortality among the elderly in New Haven, Connecticut, and Iowa and Washington Counties, Iowa, 1982-1986. Am f Epidemiol 1990;131:91-103.

6 Hirdes JP, Forbes WF. Factors associated with the Hirdes JP, Forbes WF. Factors associated with the
maintenance of good self-rated health. $f$ Aging Health 1993;5:101-22

7 Idler EL, Kasl S. Health perceptions and survival: Do global evaluations of health status really predict mortality? $\mathscr{f}$ Gerontol 1991;46:S55-65.

8 Branch LG, Ku L. Transition probabilities to dependency, institutionalization and death among the elderly over a decade. F Aging Health 1989;1:370-408.

9 Mor V, Wilcox V, Rakowski W, et al. Functional transitions among theelderly: patterns, predictors and related hospital use. Am F Public Health 1994;84:1274-80.

10 Badley EM, Yoshida K, Webster G, et al. Disablement and chronic health problems in Ontario. Ontario Health Survey 1990. Working Paper no 5. Toronto (ON): Ministry of Health, 1993.

11 Statistics Canada. General social survey. Ottawa: Statistics Canada, 1994

12 Statistics Canada. Disabled persons in Canada. Health and activity limitation survey: highlights. Cat No 82-602. Ottawa: Statistics Canada, 1990.

13 Statistics Canada. Selected characteristics of persons with disabilities residing in households: 1991 health and activity limitation survey. Cat no 82-555. Ottawa: Statistics Canada, 1994

14 D'Arcy C, Siddique CM. Health and unemployment: Findings from a national survey. Int 7 Health Serv 1985;15:609-35.

15 Wolinsky FD, Stump TE, Clark DO. Antecedents and consequences of physical activity and exercise among older sequences of physical activity and exer

16 Poikolainen K, Vartianen E, Korhonen HJ. Alcohol intake and subjective health. Am F Epidemiol 1996;144:346-50.

17 House JS, Landis KR, Umberson D. Social relationships and health. Science $1981 ; 241: 540-5$

18 Berkman LF, Syme L. Social networks, host resistance, and mortality: A nine year follow-up study of Alameda County residents. Am f Epidemiol 1979;109:176-204.

19 Kaplan BH, Cassel JC, Gore S. Social support and health. Med Care 1977;15:47-58.

20 Robinson JP, Shaver PR, Wrightsman LS. Measures of personality and social psychological attitudes: Volume I of measures of social psychological attitudes. San Diego: Academic Press, 1991.

21 Schulz R, Decker S. Long-term adjustment to physical disability: The role of social support, perceived control, and disability: The role of social support, perceived

22 Crisp R. Long-term adjustment of 60 persons with spinal cord injury. Austr Psychol 1992;27:43-7.

23 Fuhrer MJ, Randily DH, Hart A, et al. Relationship of life satisfaction to impairment, disability and handicap among persons with spinal cord injury living in the community. Arch Phys Med Rehabil 1992;73:552-7.

24 Tambay J-L, Catlin G. Sample design of the national population health survey. Health Reports, Statistics Canada 1995;7:29-38.

25 Pearlin LI, Schooler C. The structure of coping. F Health Soc Behav 1978;19:2-21.

26 Rosenberg M. Society and the adolescent self-image. Princeton, NJ: Princeton University Press, 1975.

27 Statistics Canada. National Population Health Survey 199495: Public use microdata files. Ottawa: Statistics Canada, 95: Putic

28 Zautra A, Hempel A. Subjective well-being and physical health: a narrative literature review with suggestions for health: a narrative literature review with suggestion
future research. $\mathcal{F}$ Appl Soc Psychol 1989;19:1164-81.

29 Antonovsky A. The sense of coherence as a determinant of health. In: Matarazzo S, Weiss J, Miller N, et al, eds. Behavioral health. New York: Wiley, 1984:114-29.

30 Cohen S, Wills TA. Stress, social support and the buffering hypothesis. Psychol Bull 1985;98:310-57.

31 Menec VH, Chipperfield JG. The interactive effect of perceived control and functional status on health and mortality among young-old and old-old Adults. F Gerontol 1997;52B:P118-26

32 Zautra AM, Reich JW, Newsom JT. Autonomy and sense of control among older adults: An examination of their effects on mental health. In: Bond LA, Cutler SJ, Grams A, eds. Promoting successful and productive aging. Thousand Oaks, Promoting successful and pro

33 Helgeson VS. Moderators of the relation between perceived control and adjustment to chronic illness. $\mathcal{F}$ Pers Soc Psychol 1992;63:656-66.

34 Penning MJ. Health, social support and the utilization of health services among older adults. F Geron 1995;50B: S330-9. 